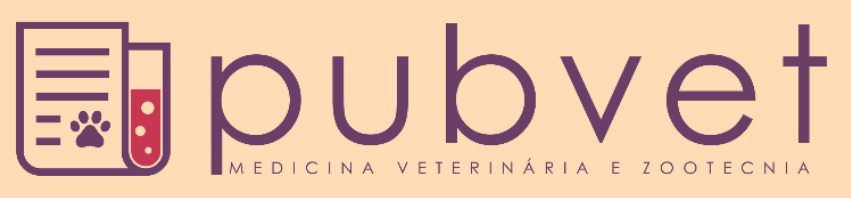

https://doi.org/10.31533/pubvet.v13n01a252.1-8

\title{
Uveíte bilateral em um equino: Relato de caso
}

\author{
Marta Eloy Nunes da Cunha*1 ${ }^{\bullet}$, Elson Nery da Silva ${ }^{\circledR}$, Daniel Bessert de Abreu ${ }^{2}$, Domingos \\ Cachineiro Rodrigues Dias ${ }^{3}$, Maria Consuêlo Caribé Ayres ${ }^{3 \bullet}$ \\ ${ }^{I}$ Médico(a) Veterinário(a) Residente em Clínica de Ruminantes e Equídeos, Universidade Federal da Bahia, Salvador, Brasil \\ ${ }^{2}$ Médico Veterinário Coordenador do Departamento Técnico de Nutrição Animal da Empresa Matsuda. \\ ${ }^{3} \operatorname{Prof}^{o}($ a) do Departamento de Anatomia, Patologia e Clínicas, Universidade Federal da Bahia, Salvador, Bahia, Brasil. \\ *Autor para correspondência, E-mail: marta.eloy@hotmail.com
}

Resumo. Dentre as principais causas de prejuízos para equideocultura destacam-se as diversas enfermidades, dentre elas as doenças oculares, em especial as queratites e uveítes. Estas apresentam origem inflamatória e estão associadas aos principais casos de cegueira nos equinos. A uveíte é por definição a inflamação do trato uveal do olho. A inflamação pode envolver íris e corpo ciliar (uveíte anterior) ou a coróide e retina (uveíte posterior). Em cavalos é mais comum à ocorrência de inflamação em todas as estruturas (panuveíte). O presente trabalho teve como objetivo relatar o caso clínico de uveíte bilateral em um equino atendido na Clínica de Equídeos do Centro de Desenvolvimento da Pecuária (CDP) da Universidade Federal da Bahia (UFBA), situado no município de Santo Amaro - BA. No presente caso clínico um equino da raça Mangalarga Marchador apresentava cegueira bilateral há aproximadamente 90 dias, sem apresentar histórico prévio de trauma ou outras afecções no globo ocular. No exame oftálmico o animal apresentava epífora e quemose bilateral, opacidade vítrea com presença de úlcera de córnea superficial central e edema de córnea bilateral. Observou-se também redução do reflexo pupilar, porém ainda presente. Reflexo palpebral presente e reflexo de ameaça ausente bilateralmente, além Teste Lacrimal de Schirmer com resultado superior a $35 \mathrm{~mm} / \mathrm{min}$ e teste da fluoresceína positivo bilateral. O animal apresentou sorologia negativa para Leptospira spp. Devido ao histórico e sinais clínicos o animal foi diagnosticado com uveíte primária. Após realização de tratamento durante 30 dias consecutivos, incluindo o uso de antimicrobianos e antiinflamatórios sistêmicos associado ao uso de tratamento tópico com colírios antibiótico e lubrificante o animal passou a apresentar notória evolução no quadro clínico, tendo uma evidente melhora na acuidade visual, a qual foi identificada após realização de exame físico geral e oftalmológico.

Palavras chave: cavalo, oftalmia, cegueira

\section{Bilateral uveitis in an equine: Case report}

Abstract. Among the main causes of damages to equideoculture are the various diseases, among them ocular diseases, especially keratitis and uveitis. These have an inflammatory origin and are associated with the main cases of blindness in horses. Uveitis is by definition the inflammation of the uveal tract of the eye. The inflammation may involve iris and ciliary body (anterior uveitis) or the choroid and retina (posterior uveitis). In horses is more common to the occurrence of inflammation in all structures (panuveitis). The objective of this study was to report the clinical case of bilateral uveitis in an equine at the Clínica de Equídeos of Centro de Desenvolvimento da Pecuária (CDP) at Universidade Federal da Bahia (UFBA), located in the city of Santo Amaro-BA. In the present case, a Mangalarga Marchador equine had bilateral blindness for approximately 90 days, without previous history of trauma or other conditions in the eyeball. In ophthalmic examination, the animal 
had bilateral epiphora and chemosis, vitreous opacity with presence of central superficial corneal ulcer and bilateral corneal edema. Reduction of pupillary reflex was also observed, but still present. Eyelid reflex present and threat reflex absent bilaterally, besides Schirmer lachrymal test with a result higher than $35 \mathrm{~mm} / \mathrm{min}$ and bilateral positive fluorescein test. The animal presented negative serology for Leptospira spp. Due to the history and clinical signs the animal was diagnosed with primary uveitis. After treatment for 30 consecutive days, including the use of antimicrobials and systemic anti-inflammatories associated with the use of topical treatment with antibiotic and lubricant eyelids, the animal presented a marked evolution, with an evident improvement in visual acuity, which was identified after physical and ophthalmologic examination.

Keywords: horse, ophthalmia, blindness

\section{Uveítis bilateral en un equino: Reporte de un caso}

Resumen. Entre las principales causas de perjuicios para la ganadería equina se destacan las diversas enfermedades, entre ellas las enfermedades oculares, en especial las queratitis y uveítis. Estas presentan origen inflamatorio y están asociadas a los principales casos de ceguera en los equinos. La uveítis es por definición la inflamación del tracto uveal del ojo. La inflamación puede envolver el iris y el cuerpo ciliar (uveítis anterior) o la coroides y retina (uveítis posterior). En caballos es más común a la ocurrencia de inflamación en todas las estructuras (panuveítis). El presente trabajo tuvo como objetivo relatar el caso clínico de uveítis bilateral en un equino atendido en la Clínica de Équidos del Centro de Desarrollo de la Ganadería (CDP) de la Universidad Federal de Bahía (UFBA), situado en el municipio de Santo Amaro - BA. En el presente caso clínico un equino de la raza Mangalarga Marchador presentaba ceguera bilateral hace aproximadamente 90 días, sin presentar antecedentes de trauma u otras afecciones en el globo ocular. En el examen oftálmico el animal presentó epífora y quemosis bilateral, opacidad vítrea con presencia de úlcera de córnea superficial central y edema de córnea bilateral. Se observó también reducción del reflejo pupilar, pero todavía presente. Reflejo palpebral presente y reflejo de amenaza ausente bilateralmente, además Test Lacrimal de Schirmer con resultado superior a $35 \mathrm{~mm}$ / min y prueba de la fluoresceína positiva bilateral. El animal presentó serología negativa para Leptospira spp. Debido al histórico y los signos clínicos, el animal fue diagnosticado con uveítis primaria. Después de la realización de tratamiento durante 30 días consecutivos, incluyendo el uso de antimicrobianos y antiinflamatorios sistémicos asociados al uso de tratamiento tópico con colirios antibiótico y lubricante el animal pasó a presentar notoria evolución en el cuadro clínico, teniendo una evidente mejora en la agudeza visual, la cual fue identificada después de la realización de un examen físico general y oftalmológico.

Palabras clave: caballo, oftalmia, ceguera

\section{Introdução}

A equídeocultura é atividade significativa no Brasil e apresenta uma densidade de 0,65 equídeos por quilômetro quadrado (ANUALPEC, 2017). Estima-se que, do total do rebanho equino brasileiro, aproximadamente 1.100 .000 cabeças sejam animais para esporte, lazer e criação, enquanto que em torno de 3.900.000 cabeças sejam de cavalos para trabalho (Lima \& Cintra, 2016). Desta forma, o Complexo do Agronegócio do Cavalo é responsável, direta e indiretamente, por cerca de três milhões de empregos.

Dentre as causas de prejuízos para equideocultura destacam-se as diversas enfermidades, dentre elas as doenças oculares, em especial as queratites e uveítes. Estas apresentam origem inflamatória e estão associadas aos principais casos de cegueira nos equinos. Dentre os animais domésticos, a espécie equina é a que apresenta maior prevalência de doenças oculares de origem infecciosa e imunomediada (Gilger \& Deeg, 2011). A uveíte é por definição a inflamação do trato uveal do olho. A inflamação pode envolver íris e corpo ciliar (uveíte anterior) ou a coróide e retina (uveíte posterior). Em cavalos é mais comum à ocorrência de inflamação em todas as estruturas (panuveíte), chegando a apresentar prevalência de até $25 \%$ nos EUA e $10 \%$ na Europa. Sendo assim, essa enfermidade oftálmica é considerada para a equideocultura mundial como uma das doenças de maior impacto econômico, com 
prejuízos anuais médios de um bilhão de dólares, sendo estes decorrentes da interrupção no treinamento, queda de desempenho atlético e desqualificação dos animais de competição (Gilger, 2017; Keller \& Hendrix, 2005; Whitley \& Gilger, 2003).

Quando se compara a atuação de profissionais e as pesquisas na área de oftalmologia equina realizados nos Estados Unidos e Europa, o Brasil ainda apresenta poucos profissionais atuantes na área da oftalmologia equina, o que torna a literatura brasileira escassa, além de limitar o desenvolvimento científico e as publicações em relação ao assunto (Machado et al., 2005).

O objetivo do presente trabalho foi relatar um caso clínico de uveíte bilateral em um equino da raça Mangalarga Marchador, atendido na clínica de equídeos do Centro de Desenvolvimento da Pecuária (CDP) da Universidade Federal da Bahia (UFBA), situado no município de Santo Amaro - BA.

\section{Relato do caso}

Em 27 de setembro de 2017, uma parte do corpo técnico do Centro de Desenvolvimento da Pecuária (CDP) da Universidade Federal da Bahia (UFBA) foi contatada para a realização de um atendimento externo a um equino macho, reprodutor, de pelagem tordilha, da raça Mangalarga Marchador, com seis anos de idade. De acordo com as informações prestadas pelo proprietário, o animal apresentava cegueira há aproximadamente 90 dias, a qual, ainda de acordo com os relatos, era apenas observada durante o período da noite. Sendo assim, o proprietário do referido animal optou por manter o mesmo estabulado na tentativa de evitar possíveis acidentes.

O animal foi inicialmente atendido na propriedade, a qual se localiza no município de EsplanadaBA, distante $155 \mathrm{~km}$ de Salvador, Bahia. A ficha clínica do atendimento é a de número 157, a atribuição da numeração é realizada de acordo com o número de animais atendidos dentro de um ano pela clínica de equídeos do Centro de Desenvolvimento da Pecuária. O referido animal identificado como Pancoso, pertencente à espécie equina, da raça Mangalarga Marchador, nascido no dia 23 de setembro de 2011, macho, não orquiectomizado, embora não possuísse histórico de coberturas nos últimos dois anos. $\mathrm{O}$ mesmo apresentava pelagem tordilha e, havia sido adquirido pelo atual proprietário havia dois anos.

A queixa principal do proprietário era a respeito do quadro de cegueira que o animal apresentava. Quadro este que o mesmo informou estar acontecendo pela primeira vez desde que o animal foi adquirido, muito embora ele não tivesse conhecimento do histórico dos anos anteriores. Ainda de acordo com o relato, a cegueira era apenas observada durante a noite e havia iniciado logo após o animal ter sido transferido para um centro de treinamento equestre (CTE), o qual apresentava grande quantidade de roedores em especial nas baias e depósitos de ração. Por motivos de insatisfação em relação à falta de higiene do local em que o animal se encontrava, o proprietário optou em transferi-lo para a sua propriedade, local onde poderia ter melhores condições de sanidade. $\mathrm{O}$ equino foi então mantido estabulado, pois havia o receio de ocorrerem acidentes devido ao quadro de cegueira.

Em relação à alimentação, era fornecido concentrado, duas vezes ao dia (manhã e tarde), totalizando quatro quilogramas, além da ração, era também fornecido feno de capim Transvaal (Digitaria decubens) em rede suspensa e à vontade. A água oferecida em bebedouro automático era encanada e devidamente tratada. Nenhum suplemento havia sido administrado no último ano. O controle de endoparasitas e ectoparasitas havia sido realizado há duas semanas, utilizando para isso, pasta oral Equest ${ }^{\circledR}$ a base de moxidectina, conforme recomendação de bula para o peso do animal. O calendário vacinal englobava apenas a realização das vacinas contra tétano, influenza, encefalomielite e raiva. Animal negativo para anemia infecciosa equina e mormo. Não havia nenhum histórico de enfermidades, procedimentos cirúrgicos ou traumas.

No exame físico inicial, realizado ainda na propriedade, foi possível observar que o animal se encontrava com escore de condição corporal três (escala de 3 a 5). Após estimativa com fita própria para a espécie obtivemos um valor equivalente a $450 \mathrm{~kg}$. Os padrões fisiológicos, incluindo frequência cardíaca e respiratória, com 38 batimentos por minuto e 14 movimentos por minuto, respectivamente. A temperatura corporal estava em $37,2^{\circ} \mathrm{C}$. Os padrões fisiológicos foram considerados sem alterações para a idade e espécie, conforme descrito por Speirs (1999). 
Com o intuito de não ocorrerem alterações nos padrões fisiológicos, os mesmos foram mensurados ainda com o animal dentro da baia, local no qual o animal se sentia confortável e confiante. Aproveitando o ambiente escuro da baia foi realizado o teste de resposta do reflexo pupilar com auxílio de feixe luminoso (lanterna), o qual se apresentou diminuído, porém ainda presente. Apesar do histórico de cegueira apenas noturna, era necessário remover o animal da baia para realizar testes que avaliassem melhor a acuidade visual, foram realizados testes do reflexo palpebral, o qual se mostrou presente, diferentemente do que ocorreu com o reflexo de ameaça, que estava bilateralmente ausente. $\mathrm{O}$ animal foi conduzido para um redondel com presença de obstáculos (local desconhecido para o animal) e logo se mostrou incapacitado em se desviar dos objetos colocados como barreiras no seu trajeto, logo, foi possível perceber que não se tratava de uma cegueira possível de ser observada apenas no período da noite.

Ainda durante a realização do exame físico específico, constatou-se que o animal apresentava turvação da córnea, epífora, blefaroespasmo, fotofobia moderadas e quemose, todas essas alterações estavam presentes bilateralmente (Figura 1).

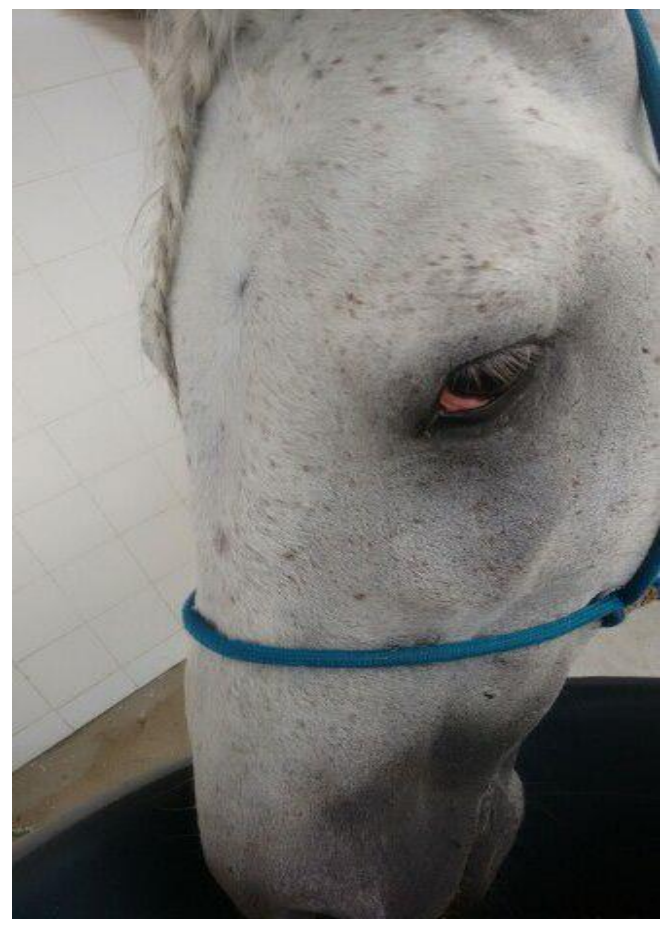

Figura 1. Equino portador de uveíte, apresentando quemose e epífora. Fonte: Arquivo pessoal

Como procedimento padrão no atendimento dos equinos, se procedeu coleta de material para realização de exames complementares, sendo solicitado hemograma, dosagem sérica das proteínas totais, creatinina, gama glutamil transferase (GGT), aspartato amino transferase (AST) e ureia, além de sorologia para Lepstospira spp. Os componentes do hemograma encontravam-se dentro dos valores de referência para a espécie (Tabela 1). Os valores encontrados nas dosagens séricas também foram considerados dentro dos valores de referência, com exceção da proteína sérica total que se encontrava discretamente abaixo dos valores esperados para a espécie (Tabela 2).

Tendo em vista que o tratamento para as enfermidades oftálmicas necessitam de suporte e pessoal disponível para realização do mesmo, optou-se pelo internamento do animal na clínica de Equídeos do CDP-UFBA, local onde poderia ter melhor suporte para realização do tratamento necessário, além de ser possível realizar acompanhamentos periódicos para avaliação da evolução do quadro clínico.

O animal foi internado na clínica de Equídeos do CDP-UFBA no dia 28 de setembro de 2017 e foi solicitado realização de exames oftálmicos mais específicos como a tonometria, teste lacrimal de Schirmer, além da aplicação de fluoresceína para avaliação da presença de úlceras de córnea. O exame oftálmico foi realizado no dia 5 de outubro de 2017. A avaliação foi realizada em sala escura, com auxílio de lanterna de luz halógena e fonte de magnificação (lupa de pala) utilizados em exames 
oftálmicos de rotina: Teste Lacrimal de Schirmer com resultado superior a $35 \mathrm{~mm} / \mathrm{min}$ (tiras comerciais podem saturar por completo devido à grande produção lacrimal para a espécie); inspeção da superfície ocular em ambiente escuro com auxílio da lanterna; e teste da fluoresceína, com resultado positivo bilateral. O animal apresentou discreta epífora e quemose bilateral, opacidade vítrea com presença de úlcera de córnea superficial central e edema de córnea bilateral. Observou-se também redução do reflexo pupilar, porém ainda presente. Reflexo palpebral presente e reflexo de ameaça ausente bilateralmente.

Tabela 1. Valores hematológicos no momento do primeiro atendimento em setembro de 2017.

\begin{tabular}{lcc}
\hline & Valores Encontrados & Valores de Referência. Cowell \& Tyler (2001) \\
\hline VG $(\%)$ & 32,0 & $32,0-48,0$ \\
Hemácias $\left(\mathrm{x} 10^{6 / \mu \mathrm{L})}\right.$ & 6,2 & $6,0-12,0$ \\
Hemoglobina $(\mathrm{g} / \mathrm{dL})$ & 10,6 & $10,0-18,0$ \\
VGM (fL) & 51,6 & $34,0-58,0$ \\
CHGM (\%) & 33,1 & $31,0-37,0$ \\
PPT (g/dL) & 5,4 & $6,0-8,5$ \\
Fibrinogênio & 200 & $100-500$ \\
Leucócitos $(/ \mu \mathrm{l})$ & 9.750 & $6.000-12.000$ \\
Segmentados & 5460 & $3.000-6.000$ \\
Eosinófilos & 98 & $0-800$ \\
Linfócitos & 3998 & $1.500-5.000$ \\
Monócitos & 195 & $0-100$ \\
\hline
\end{tabular}

Com base no histórico, dados da anamnese e sinais encontrados nos exames clínicos gerais e específicos (exame oftálmico), diagnosticou-se o caso como uveíte bilateral aguda. A causa desencadeante não foi elucidada, uma vez que a sorologia para Leptospira spp teve resultado negativo e não havia histórico de afecções e/ou traumas anteriores.

A terapia instituída baseou-se no uso de antimicrobiano enrofloxacina (Zelotril ${ }^{\circledR}$ ), na dose de 7,5 $\mathrm{mg} / \mathrm{kg}$, IV, SID, diluído em $500 \mathrm{ml}$ de solução $\mathrm{NaCl}$ 0,9\%, durante trinta dias consecutivos. Além de terapia anti-inflamatória sistêmicos com flunexin meglumine (Desflan ${ }^{\circledR}$ ), na dose de $1.1 \mathrm{mg} / \mathrm{kg}, \mathrm{IV}, \mathrm{SID}$, durante cinco dias consecutivos. Após a terapêutica instituída com flunexin meglumine iniciou-se a terapia com meloxican (Maxican ${ }^{\circledR}$ ), na dose de $0.4 \mathrm{mg} / \mathrm{kg}$, IV, SID, durante dez dias consecutivos e após o término do uso do flunixin meglumine. A terapia sistêmica foi associada ao uso tópico de lubrificante ocular a base de carboximetilcelulose (OU/TID/20 dias) e colírio antibiótico (ciprofloxacino colírio OU/QID/20 dias) para tratamento da úlcera de córnea superficial.

Tabela 2. Valores séricos de proteína e frações, AST, GGT, ureia e creatinina no momento do primeiro atendimento em setembro de 2017.

\begin{tabular}{lcc}
\hline & Valores Encontrados & Valores de Referência, Cowell \& Tyler (2001) \\
\hline Proteína Total (mg/dL) & 5,2 & $6,0-8,5$ \\
Albumina (mg/dL) & 2,3 & $2,60-3,70$ \\
Globulinas (mg/dL) & 2,9 & $2,62-4,04$ \\
AST (U.I./L) & 363 & $226-366$ \\
GGT (U.I./L) & 10,7 & $4,3-13,4$ \\
Ureia (mg/dL) & 47 & $21,4-51,36$ \\
Creatinina (mg/dL) & 1,6 & $1,2-1,9$ \\
\hline
\end{tabular}

Após completa realização do tratamento durante os 30 dias estabelecidos, o animal acima descrito foi reavaliado e foi observado melhora do quadro inflamatório e boa resposta da acuidade visual. Houve redução do edema de córnea em olho esquerdo e regressão completa de edema em córnea do olho direito. Todavia, após realização de novo exame oftalmológico em sala escura, com auxílio de lanterna de luz halógena e fonte de magnificação (lupa de pala) notou-se presença de catarata capsular posterior insipiente em ambos os olhos. O teste de fluoresceína foi negativo constatando a completa cicatrização das úlceras de córnea. Após realização da segunda avaliação oftálmica e observação de melhora tanto 
do quadro inflamatório inicial quanto na acuidade visual, o animal recebeu alta médica hospitalar e retornou a propriedade (Figura 2). Foi solicitado ao proprietário observação do animal para ocorrência de possíveis recidivas dos sinais clínicos, e para o processo de amadurecimento da catarata e suas consequências.

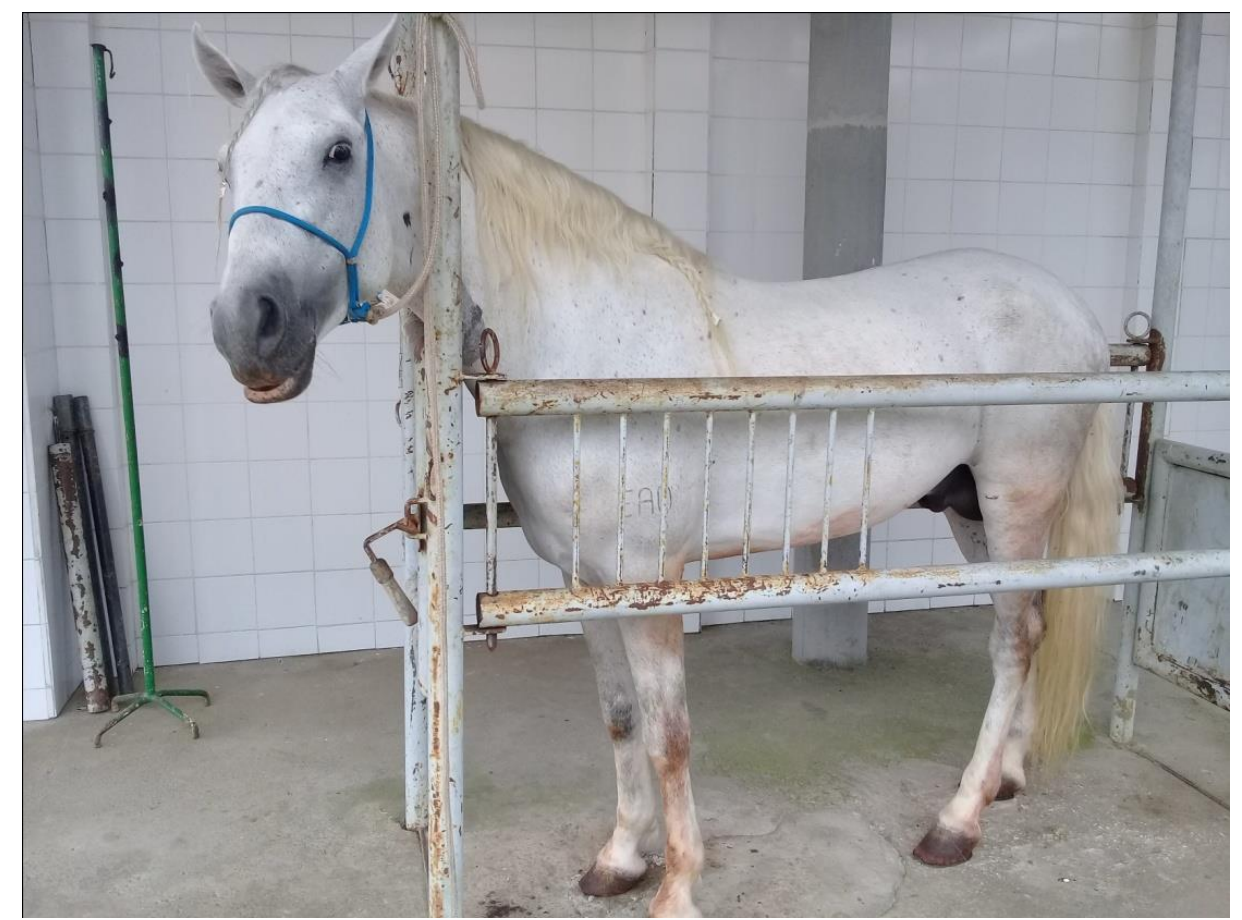

Figura 2. Equino, 30 dias após realização de tratamento, apresentando considerável melhora no quadro clínico. Fonte: Arquivo pessoal

\section{Discussão}

Dentre as causas mais comumente associadas aos quadros de cegueira na espécie equina estão as inflamações oculares, como as ceratites e uveítes, assim como ocorreu no presente relato (Gilger \& Deeg, 2011). A uveíte recorrente equina (URE) é considerada a principal causa de cegueira em equinos. Em levantamento realizado por Reichmann et al. (2008) observou-se uma incidência de $8 \%$ da enfermidade em equinos que apresentavam doenças oftalmológicas.

De acordo com Gilger (2017), a uveíte na sua fase aguda apresenta sinais como: marcada quemose, epífora, blefarospasmo e fotofobia, estes sinais foram claramente observados no presente relato. Todavia, Gilger (2017) ainda descreve a miose como um importante sinal de uveíte ativa. Entretanto, este sinal não foi observado devido ao longo período de manifestação e perpetuação dos sinais. Os demais sinais observados como, opacidade vítrea, edema e úlcera de córnea são descritos por Townsend (2012), sendo a opacidade vítrea decorrente da ruptura na barreira hemato-ocular levando a um aumento da permeabilidade vascular. O aparecimento de catarata capsular posterior é comumente observado em casos onde há cronicidade ou recorrência da uveíte, conforme descrito por Gilger \& Deeg (2011). Outras sequelas como, glaucoma, sinéquias, cicatrizes na córnea e phthisis bulbi, não foram observadas. De acordo com Dearo \& Souza (2000), o diagnóstico da uveíte deve basear-se fundamentalmente nos achados do exame clínico, além do histórico de episódios da doença ocular, assim como foi realizado no presente relato. Segundo Townsend (2012), devido ao caráter multifatorial da uveíte, além do exame físico geral, faz-se necessário a realização de um hemograma e um perfil bioquímico sérico, estes exames podem ser um apoio precioso no diagnóstico de patologias sistêmicas subjacentes, procedimentos esses também realizados no presente relato com o intuído de identificar a causa desencadeante da enfermidade.

Gilger (2017) salienta a importância em diferenciar a ocorrência de uveíte primária de URE clássica e para isso a obtenção de um histórico detalhada da ocorrência de episódios anteriores de inflamação deve ser obtida com o proprietário ou responsável pelo animal. No entanto, muitas vezes o histórico 
pode ser desconhecido e a observação associada de pelo menos três sinais da doença pode ser importante antes de fazer um diagnóstico presuntivo de URE. Os sinais incluem a atrofia dos corpora nigrans, pigmento na face anterior da cápsula da lente, sinéquias, fibrose ou mudança de cor da íris, catarata, luxação ou subluxação da lente, opacidade vítrea, descolamento de retina ou bandas de tração, cicatrizes peripapilares num padrão focal ou alar. No referido relato por falta de histórico da ocorrência de inflamações oculares nos anos anteriores a aquisição do animal e com base na ocorrência de apenas dois sinais da doença (catarata e opacidade vítrea), o animal foi diagnosticado como portador de uveíte primária, não descartando a possibilidade de uma recorrência.

Embora apresente origem multifatorial, atualmente está provado que a Leptospira spp é um dos agentes mais frequentemente associados à URE (Curling, 2011; Dwyer et al., 1995; Gilger \& Deeg, 2011). Apesar da forte ligação entre a ocorrência de uveíte e leptospirose, no presente relato a sorologia realizada com o intuito de diagnosticar Leptospira spp, foi negativa. Assim como ocorreu em relato realizado por Brandes et al. (2007) utilizando 117 equinos com URE, cerca de 20\% dos animais apresentaram soronegatividade para Leptospira spp.

De acordo com Curling (2011), para a realização de um tratamento adequado nos casos de animais portadores de uveíte é de fundamental importância o conhecimento e a consequente eliminação da causa primária, no entanto, como na maioria das vezes a afecção primária não é determinada, a instituição do tratamento é baseada na resolução dos sinais clínicos. No presente relato apesar de não ter sido diagnosticado a causa desencadeante da uveíte, realizou-se tratamento com o intuito de solucionar os sinais clínicos apresentados pelo animal.

Segundo Hines (2014), o protocolo de tratamento inicial da uveíte deve consistir da associação entre o uso de midriáticos e ciclopégicos, (atropina) na tentativa de diminuir o desconforto ocular (causado pela miose), no entanto o animal do referido relato não apresentou miose, não sendo, portanto utilizado esse tipo de medicação. A utilização de AINE's sistêmicos para reduzir a inflamação, no entanto foi realizada, utilizando para isso flunixin meglumine $(1,1 \mathrm{mg} / \mathrm{kg}$ a cada 12 horas $\mathrm{IV}$, durante cinco dias). O flunixin meglumine é um dos AINE's mais potentes no tratamento de afecções do globo ocular (Gilger \& Michau, 2004). A ocorrência de possíveis efeitos colaterais em nível de rim e sistema gastrointestinal provocado pelo uso prolongado de flunixin meglumine, após cinco dias de tratamento com a referida droga, optou-se pela substituição pelo uso de outro AINE's, o meloxican. O qual por possuir baixa ação em cicloxigenase-1(COX-1) minimiza o potencial de danos ao trato gastrintestinal.

O tratamento com corticosteroides tópicos apesar de apresentarem efeitos positivos nos casos de uveíte, podem, em outras situações como nas úlceras de córnea causar efeitos colaterais indesejáveis devido à supressão da epitelização corneana, pela potencialização da atividade da enzima colagenase, logo, seu uso em casos de úlceras de córnea é contraindicado. Assim como ocorreu com o equino do presente relato, devido à presença de úlcera de córnea bilateral, o uso tópico de corticosteroide tópico foi descartado.

Como descrito por Lavach (1990), pelo motivo de apresentar uma diferença temporal entre a infecção e o desenvolvimento de uveíte, nem sempre é possível afirmar que um resultado sorológico negativo signifique necessariamente que a uveíte não está associada à infecção por Leptospira spp. Devido ao fato de que o tratamento para uveíte tem que ser realizado o mais rapidamente possível e de forma rigorosa, por esta ser a principal causa de perda da visão, no presente relato optou-se por associar ao tratamento tópico o uso de antimicrobianos sistêmicos, a base de enrofloxacina, durante um período de quatro semanas na tentativa de eliminar possíveis casos de recorrência da uveíte, conforme descrito na literatura (Gilger \& Deeg, 2011; Hines, 2014). Segundo Hartley (2011), animais que apresentaram apenas um episódio de uveíte não podem ser considerados como portadores de URE até que uma recidiva ocorra. No entanto, o risco de vir a desenvolver esta enfermidade mais tarde, em especial nos dois anos seguintes, é bastante elevado e deve sempre ser considerado, no presente relato não tivemos tempo hábil para avaliar a ocorrência de possíveis recidivas, no entanto o proprietário foi alertado dessa possibilidade bem como da presença de catarata, o processo de amadurecimento, e as possíveis consequências da mesma para a visão do animal. 


\section{Conclusões}

A partir do presente relado, foi possível concluir que o tratamento para uveíte, realizado com associação entre o uso tópico de colírios antibiótico e lubrificante e terapia sistêmica a base de antimicrobianos e anti-inflamatórios, seguindo um protocolo de administração disciplinada, respeitando-se a dose e o horário de cada medicação, foi essencial para obtenção do sucesso no tratamento e para que possíveis consequências como quadros de cegueira parcial e até mesmo total fossem evitados.

\section{Referências bibliográficas}

ANUALPEC. (2017). Anuário da Pecuária Brasileira (20th ed. Vol. 1). São Paulo, SP, Brasil: Instituto FNP.

Brandes, K., Wollanke, B., Niedermaier, G., Brem, S. \& Gerhards, H. (2007). Recurrent uveitis in horses: vitreal examinations with ultrastructural detection of leptospires. Journal of Veterinary Medicine Series A, 54(5), 270-275.

Cowell, R. L. \& Tyler, R. D. (2001). Diagnostic cytology and hematology of the horse E-Book. Amsterdam, Holanda: Elsevier Health Sciences.

Curling, A. (2011). Equine recurrent uveitis: classification, etiology, and pathogenesis. Compendium Continuig Education for Veterinarians, 33(6), E2.

Dearo, A. C. O. \& Souza, M. S. B. (2000). Uveíte recorrente eqüina (cegueira da lua). Ciência Rural, 30(2), 373-380.

Dwyer, A. E., Crockett, R. S. \& Kalsow, C. M. (1995). Association of leptospiral seroreactivity and breed with uveitis and blindness in horses: 372 cases (1986-1993). Journal of the American Veterinary Medical Association, 207(10), 1327-1331.

Gilger, B. C. (2017). Equine ophthalmology. Iowa, USA: John Wiley e Sons Inc.

Gilger, B. C. \& Deeg, C. (2011). Equine recurrent uveitis. In B. C. Gilger (Ed.), Equine ophthalmology (pp. 317-349). Missouri, USA: Elsevier.

Gilger, B. C. \& Michau, T. M. (2004). Equine recurrent uveitis: new methods of management. Equine Practice, 20(2), 417-427.

Hartley, C. (2011). Recurrent uveitis: Diagnosis and management. Liverpool, UK: Congresso BEVA.

Hines, M. T. (2014). Leptospirosis. In S. D.C \& L. M.T. (Eds.), Equine infectious diseases (pp. 302310). St Louis, USA: Saunders Elsevier.

Keller, R. L. \& Hendrix, D. V. H. (2005). Bacterial isolates and antimicrobial susceptibilities in equine bacterial ulcerative keratitis (1993-2004). Equine Veterinary Journal, 37(3), 207-211.

Lavach, J. D. (1990). Large animal ophthalmology: Mosby CO.

Lima, R. A. S. \& Cintra, A. G. (2016). Revisão do estudo do complexo do agronegócio do cvalo. Brasília, Brasil: MAPA.

Machado, M. L. S., Oliveira, L. O., Beck, C. A. C., Conceição, M. S. N., Ferreiro, L. \& Driemeier, D. (2005). Ceratomicose eqüina causada por Aspergillus flavus. Acta Scientiae Veterinariae, 33(2), 219-223.

Reichmann, P., Dearo, A. C. d. O. \& Rodrigues, T. C. (2008). Occurrence of ophthalmologic diseases in horses used for urban cart hauling in Londrina, PR, Brazil. Ciencia Rural, 38(9), 2525-2528.

Speirs, V. C. (1999). Exame clínico de eqüinos. Porto Alegre, Rio Grande do Sul, Brasil: Artmed.

Townsend, W. M. (2012). Intraocular surgery. In J. A. Auer \& J. A. Stick (Eds.), Equine surgery (pp. 792-798): Elsevier Saunders.

Whitley, R. D. \& Gilger, B. C. (2003). Doenças e cirurgia da córnea e esclera. In K. N. Gelatt (Ed.), Manual de oftalmologia veterinária (pp. 125-164). São Paulo, Brasil: Manole.

Recebido: 20 novembro, 2018.

Aprovado: 11 dezembro, 2018

Publicado: 28 janeiro, 2019.

Licenciamento: Este artigo é publicado na modalidade Acesso Aberto sob a licença Creative Commons Atribuição 4.0 (CC-BY 4.0), a qual permite uso irrestrito, distribuição, reprodução em qualquer meio, desde que o autor e a fonte sejam devidamente creditados 